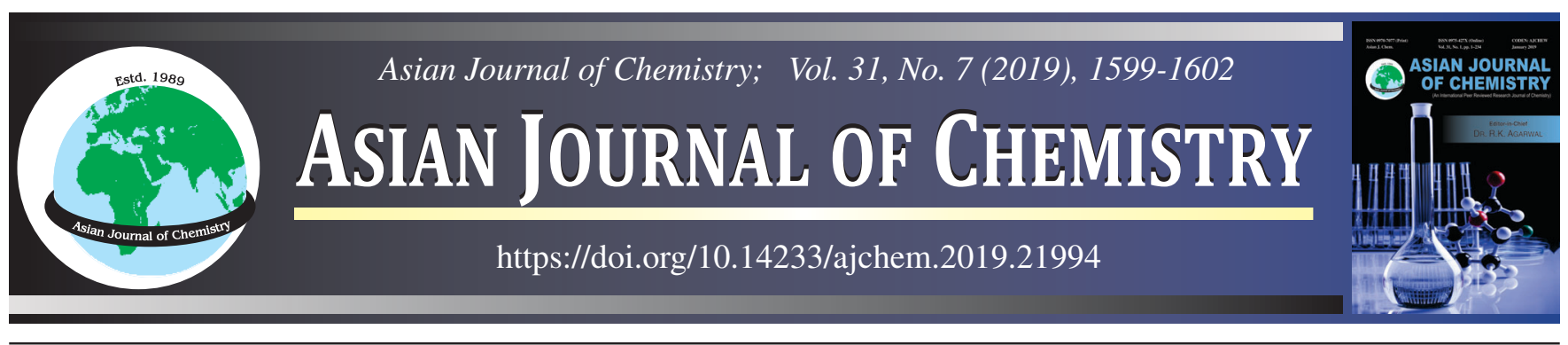

\title{
A Scalable and High-Yielding Synthesis of 2-(2-Furyl)-1,3-dioxolane from Biomass Derived Furfural and Ethylene Glycol Using Heteropoly Acids as Green Catalyst
}

\author{
R. TIWARI ${ }^{\oplus}$, S.S. MAL ${ }^{*} \bullet$ and S. DUTTA ${ }^{*} \odot$ \\ Department of Chemistry, National Institute of Technology Karnataka, Surathkal-575025, India \\ *Corresponding authors: Tel: +91 824 2473213; E-mail: malss@ nitk.edu.in; sdutta@nitk.edu.in
}

Received: 11 February 2019; Accepted: 10 April 2019;

Published online: 21 May 2019;

In present work, Keggin-type commercial heteropoly acids have been employed as efficient solid acid catalysts in the acetalization of biomass-derived furfural with ethylene glycol. The reaction was optimized on parameters such as the type and loading of catalyst, duration of reaction and the relative ratio of reagents. The reaction was scaled up and the cyclic acetal 2-(furan-2-yl)-1,3-dioxolane was isolated in $92 \%$ yield within $4 \mathrm{~h}$ using only $2 \mathrm{wt} \%$ of phosphotungstic acid in refluxing benzene.

Keywords: Furfural, Heteropoly acid, Acetalization, Biomass, Renewable synthesis.

\section{INTRODUCTION}

At present, more than $95 \%$ of chemicals and materials are derived from fossilized carbon resources. During the past several years, significant attention has been given in the production of existing and new generation chemicals and materials from renewable carbon resources [1]. In a biorefinery concept, biomass especially non-food waste biomass can be used as renewable and economically competitive carbon-based feedstock for the production of many existing and novel product classes [2]. Furfural is a well-known biomass-derived renewable chemical building block produced by acid-catalyzed dehydration of pentose sugars in the hemicellulose fraction of biomass [3]. Furfural and its derivatives have several commercial applications including fuels and fuel additives, solvents, chemical feedstock, monomers for polymers, agrochemicals and pharmaceuticals [4]. Furfural is listed as one of the top ten renewable chemical building blocks of significant commercial potential $[5,6]$. Several high-value commodity chemicals including 2-methylfuran, 2-methyltetrahydrofuran, succinic acid, maleic anhydride and furfuryl alcohol are sourced from furfural $[7,8]$. The commercial feasibility of these products relies on the scalability of the reaction, process economics and yield of the product. Reaction centres in furfural are the aldehyde functionality and the furan ring itself. For selective reactions involving the furan ring, the highly reactive aldehyde group may have to be masked temporarily. Acetalization is a routinely used strategy to temporarily mask aldehydes and ketones in multi-step syntheses. 2-(2-Furyl)-1,3-dioxolane (1) has been prepared by reacting furfural and ethylene glycol in the presence of various acid catalysts. Synthesis of $\mathbf{1}$ has been attempted using photocatalyst [9], acidic ionic liquids [10], metal salts $[11,12]$ and sulphonic acids [13]. High yield of $\mathbf{1}$ is often ensured by using excess alcohol and/or continuous removal of the water byproduct. In this regard, heteropoly acids (HPAs) have been used as efficient and green acid catalyst for a host of organic transformations. Heteropoly acids are increasingly being used in the chemistry of renewables [14-16]. Heteropolyacid-based catalysts have desirable properties including strong acidity, low toxicity, less corrosive nature, well-defined structure, high thermal stability and tuneable solubility [1720]. In this work, we report the synthesis of $\mathbf{1}$ from furfural and ethy-lene glycol using commercial heteropoly acid catalysts (Scheme-I). The reaction was optimized on the duration of reaction, type and amount of water removal agent, ratio of furfural and ethylene glycol, type and loading of heteropoly acid catalyst.<smiles>O=Cc1ccco1</smiles>
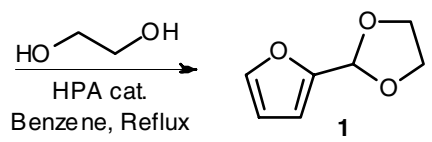

Scheme-I: Preparation of $\mathbf{1}$ from furfural using heteropoly acid catalysts

This is an open access journal, and articles are distributed under the terms of the Creative Commons Attribution-NonCommercial-ShareAlike 4.0 (CC BY-NC-SA 4.0) International License which allows readers to freely read, download, copy, distribute, print, search, or link to the full texts of its articles and to use them for any other lawful non-commercial purpose as long as the original source is duly acknowledged. 


\section{EXPERIMENTAL}

The catalysts, namely, phosphotungstic acid (PTA), silicotungstic acid (STA), phosphomolybdic acid (PMA), and silicomolybdic acid (SMA) were purchased from Sigma Aldrich and dried overnight in a hot-air oven at $110^{\circ} \mathrm{C}$ before use. Furfural (99\%) was purchased from Loba Chemie Pvt. Ltd. and distilled under reduced pressure before use. Benzene (99.5\%), ethylene glycol (99\%), sodium sulphate (anhydrous) and chloroform (99\%) were purchased from Loba Chemie Pvt. Ltd. The solvents were dried over activated molecular sieved (4 $\AA$ ) prior use.

Reaction procedure: In a $50 \mathrm{~mL}$ round-bottomed flask, furfural $(0.500 \mathrm{~g}, 5.2 \mathrm{mmol})$, ethylene glycol $(0.96 \mathrm{~g}, 15.4$ mmol, 3 eq.) and PTA catalyst $(0.010 \mathrm{~g}, 2 \mathrm{wt} \%)$ were added. In the mixture, $20 \mathrm{~mL}$ dry benzene and a magnetic stir bar were added. The flask was connected to a Dean-Stark apparatus and placed in a pre-heated oil bath. The reaction mixture was magnetically stirred during the reaction. The progress of the reaction was monitored by TLC and FTIR. After completion of the reaction, the mixture was cooled and filtered. This solid residue on the filter paper containing catalyst was washed with chloroform. The combined solvent was dried over anhydrous $\mathrm{Na}_{2} \mathrm{SO}_{4}$ and evaporated under reduced pressure in a rotary evaporator. The crude product was chromatographed over silica gel (60-120 mesh, deactivated by triethylamine) using chloroform as eluent. The solvent was evaporated under reduced pressure to provide $\mathbf{1}(0.670 \mathrm{~g}, 92 \%)$ as a light brown liquid. ${ }^{1} \mathrm{H}$ NMR $\left(400 \mathrm{MHz}, \mathrm{CDCl}_{3}\right): 7.44(1 \mathrm{H}, \mathrm{s}), 6.46(1 \mathrm{H}, \mathrm{s}), 6.37$ $(1 \mathrm{H}, \mathrm{s}), 5.94(1 \mathrm{H}, \mathrm{s}), 4.15(2 \mathrm{H}, \mathrm{t}), 4.02(2 \mathrm{H}, \mathrm{t}) .{ }^{13} \mathrm{C}$ NMR $(100$ $\left.\mathrm{MHz}, \mathrm{CDCl}_{3}\right): 151.1,143.1,110.1,108.7,97.7,65.1$. FTIR (ATR, $\mathrm{cm}^{-1}$ ): 3148, 3123, 2956, 2891, 1093, 940.

\section{RESULTS AND DISCUSSION}

The acetalization of furfural with ethylene glycol was performed using heteropoly acid catalysts under conventional heating and magnetic stirring. The reaction flask was connected to a Dean-Stark apparatus for azeotropic removal of water byproduct using benzene. Four commercial heteropoly acids namely, phosphotungstic acid (PTA), silicotungstic acid (STA), phosphomolybdic acid (PMA) and silicomolybdic acid (SMA) were examined for their efficiency in producing 1 . The reaction was monitored by TLC and FTIR spectroscopy where aliquots were withdrawn at regular intervals and examined for complete conversion of furfural. Conversion of furfural remained low even after overnight reaction using three equivalents of ethylene glycol and $10 \mathrm{wt} \%$ of PTA catalyst when the reaction was conducted at room temperature. On the other hand, the reaction completed within $4 \mathrm{~h}$ in refluxing benzene using only three equivalents of ethylene glycol and $2 \mathrm{wt} \%$ of heteropoly acid catalyst. At shorter reaction time, the conversion of furfural did not reach $100 \%$. Formation of $\mathbf{1}$ was not observed in the control reaction without using heteropoly acid catalyst. Among the heteropoly acids examined, PTA showed best catalytic activity providing $92 \%$ isolated yield of $\mathbf{1}$ whereas the other three heteropoly acid catalysts (i.e., STA, PMA and SMA) gave only around $70 \%$ (Fig. 1). Decomposition of furfural into insoluble humin was observed in all cases but significantly less in the case of PTA, which indirectly supports the observed

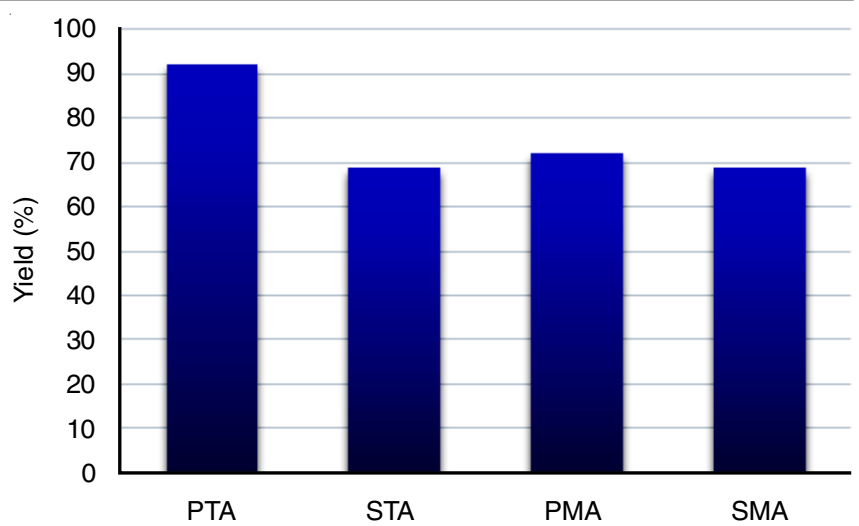

Fig. 1. Effects of various heteropoly acids catalysts on the yield of $\mathbf{1}$. Reaction condition: Furfural $(0.5 \mathrm{~g}, 5.2 \mathrm{mmol})$, ethylene glycol $(0.96 \mathrm{~g}, 15.4 \mathrm{mmol}, 3 \mathrm{eq})$, reflux, $4 \mathrm{~h}$, heteropoly acid $(0.01 \mathrm{~g}, 2 \mathrm{wt}$ $\%)$, benzene $(20 \mathrm{~mL})$

high yield of $\mathbf{1}$. High yield in PTA may be explained by the relatively stronger acidity of PTA compared to other heteropoly acids examined [21]. Since PTA catalyst exhibited the best catalytic performance, it was chosen for further optimizations.

Loading of PTA catalyst was varied to study its effect on the yield of $\mathbf{1}$ (Fig. 2). The amount of PTA catalyst was varied between 1-6 wt \% compared to furfural while keeping other optimized parameters constant. Although the reaction completed within $4 \mathrm{~h}$ even with $1 \mathrm{wt} \%$ loading of PTA catalyst, the yield was only $85 \%$. Increasing the loading to $2 \mathrm{wt} \%$ increased the yield to $92 \%$. However, further increase in wt $\%$ of catalyst slightly decreased the yield but remained around $90 \%$ up to 4 wt $\%$ of PTA. The improvement in yield of $\mathbf{1}$ between 1-2 wt \% loading of PTA catalyst is due to the increase in the number of acidic sites available.

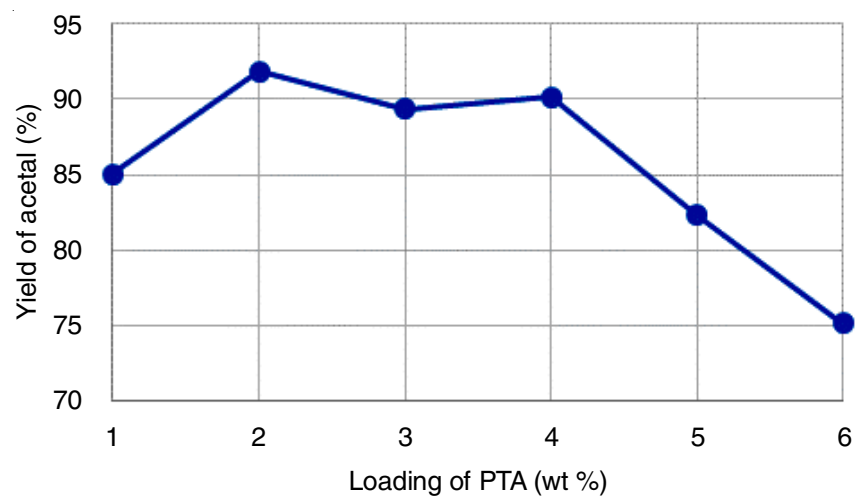

Fig. 2. Effect of catalyst loading of PTA catalyst on the yield of $\mathbf{1}$. Reaction condition: Furfural $(0.5 \mathrm{~g})$, ethylene glycol (0.96 g), reflux, $4 \mathrm{~h}$, benzene $(20 \mathrm{~mL})$

However, when higher loading of the catalyst was used, the yield of $\mathbf{1}$ decreased to 82 and $75 \%$ at 5 and 6 wt \% PTA, respectively. This decrease in the yield of $\mathbf{1}$ may be due to acid-catalyzed side reactions such as resinification of furfural. The effect of molar ratio of furfural and ethylene glycol on the yield of $\mathbf{1}$ was also studied. Due to the reversible nature of the acetalization reaction, better yields of acetal are generally obtained in the presence of excess alcohol. However, use of excess alcohol introduces additional steps of product purification and recovery of unreacted alcohol. Therefore, the effects 
of the various molar ratios of ethylene glycol over furfural were studied using $2 \mathrm{wt} \%$ PTA catalyst in refluxing benzene. Molar ratio of ethylene glycol: furfural was varied between 2:1 to 5:1 (Fig. 3). The conversion of furfural was not complete even after $6 \mathrm{~h}$ under refluxing benzene when less than two equivalent of ethylene glycol was used. Increasing the ratio from 2:1 to 3:1 increased the yield of $\mathbf{1}$ from 79 to $92 \%$. However, a further increase in the equivalent of ethylene glycol lowered the yield of $\mathbf{1}$. The lowering of yield of $\mathbf{1}$ at more than three equivalent of ethylene glycol may be explained by the dilution of the reactant.

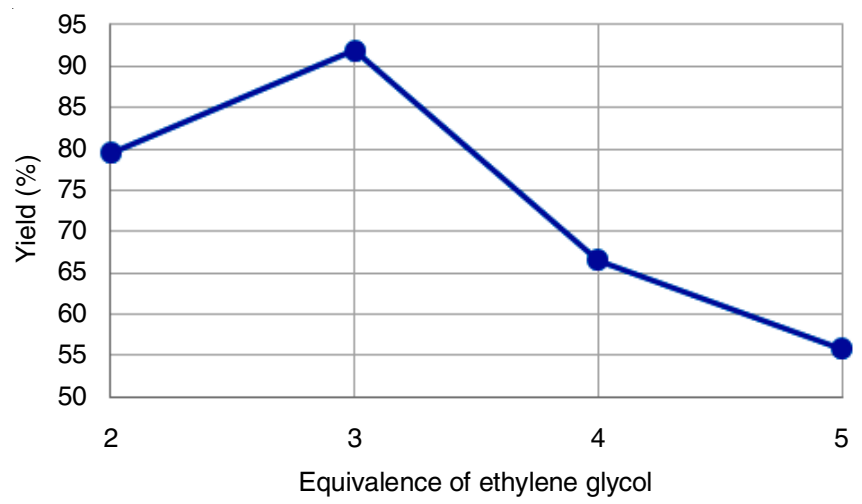

Fig. 3. Effect of the molar ratio between ethylene glycol and furfural on the isolated yield of $\mathbf{1}$

The efficiency of benzene in removing water from the reaction mixture by azeotropic distillation was compared with other commonly used solvents like cyclohexane and toluene (Fig. 4). Under identical conditions, benzene was found most efficient for the synthesis of $\mathbf{1}$. Whereas toluene behaved better than cyclohexane, it provided considerably lower yield of $\mathbf{1}$ than benzene. Interestingly, without the azeotropic removal of water, the reaction did not complete even after several hours and led to increasing humin formation over time.

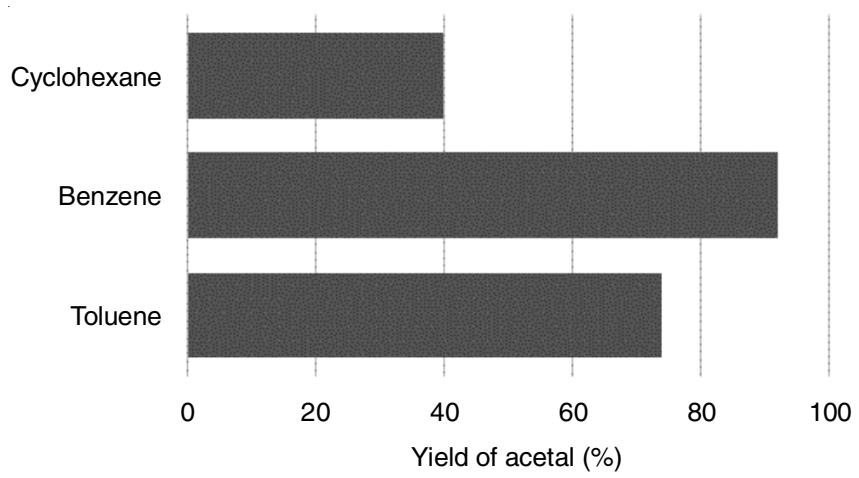

Fig. 4. Effect of solvent on the yield of $\mathbf{1}$. Reaction condition: Furfural (0.5 g), ethylene glycol (0.96 g), PTA (0.01 g), reflux, $4 \mathrm{~h}$, solvent $(20 \mathrm{~mL})$

The amount of benzene varied to observe its effect on the yield of 1 (Fig. 5). Whereas less amount of benzene $(<15 \mathrm{~mL})$ led to incomplete reaction and poor yields of $\mathbf{1}$, use of $20 \mathrm{~mL}$ benzene provided the best yield. Higher amounts of benzene drops the yield of 1 again due to the dilution affect. The reaction was scaled up to $5 \mathrm{~g}$ of furfural. The reaction completed within $4 \mathrm{~h}$ in refluxing benzene and provided $\mathbf{1}$ in $90 \%$ isolated yield.

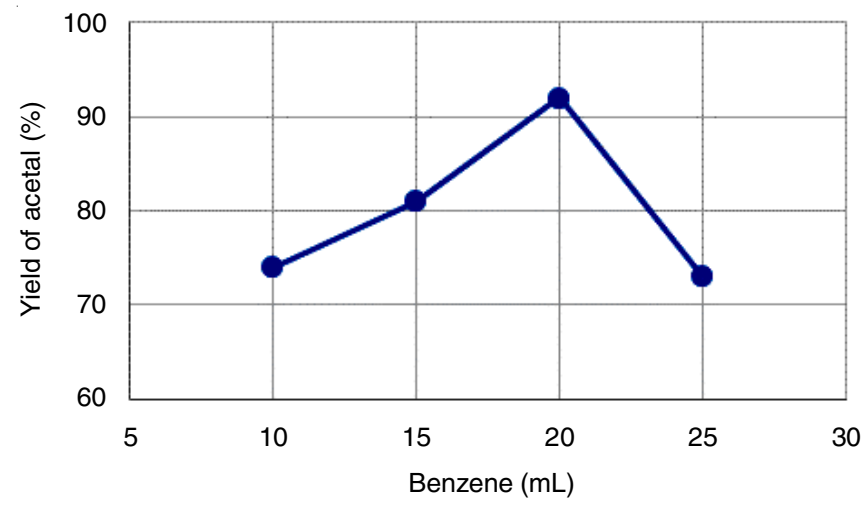

Fig. 5. Effect of varying quantity of benzene on the yield of $\mathbf{1}$. Reaction condition: Furfural (0.5 g), ethylene glycol (0.96 g), PTA (0.01 g), reflux, $4 \mathrm{~h}$

\section{Conclusion}

Heteropoly acids have been used as efficient acid catalyst for the synthesis of 2-(furan-2-yl)-1,3-dioxolane from biomassderived furfural and ethylene glycol. The cyclic acetal was isolated in $92 \%$ yield using 1:3 molar ratio of furfural and ethylene glycol and only 2 wt $\%$ of phosphotungstic acid catalyst. The catalyst was conveniently separated from the reaction mixture by exploiting the differential solubility of heteropoly acids catalysts.

\section{ACKNOWLEDGEMENTS}

The authors thank Science and Technology Research Board (SERB), India for funding support under the schemes SB/FT/ CS-077/2014 and YSS/2015/001649. One of the authors, RT is thankful to National Institute of Technology Karnataka, Surathkal, India for the research fellowship.

\section{CONFLICT OF INTEREST}

The authors declare that there is no conflict of interests regarding the publication of this article.

\section{REFERENCES}

1. A.J. Ragauskas, C.K. Williams, B.H. Davidson, G. Britovsek, J. Cairney, C.A. Eckert, W.J. Frederick Jr., J.P. Hallett, D.J. Leak, C.L. Liotta, J.R. Mielenz, R. Murphy, R. Templer and T. Tschaplinski, Science, 311, 484 (2006);

https://doi.org/10.1126/science.1114736.

2. M. Stöcker, Angew. Chem. Int. Ed., 47, 9200 (2008); https://doi.org/10.1002/anie.200801476.

3. J.-P. Lange, E. van der Heide, J. van Buijtenen and R. Price, ChemSusChem, 5, 150 (2012); https://doi.org/10.1002/cssc. 201100648.

4. J.C. Serrano-Ruiz, R.M. West and J.A. Dumesic, Ann. Rev. Chem. Biomol., 1. 79 (2010);

https://doi.org/10.1146/annurev-chembioeng-073009-100935.

5. A. Aden, J. Bozell, J. Holladay, J. White and A. Manheim, eds.: T. Werpy and G. Petersen, Results of Screening for Potential Candidates from Sugars and Synthesis Gas; In: Top Value Added Chemicals from Biomass, U.S. Department of Energy, Oak Ridge, TN, vol. 1, August (2004); Available at www.eere.energy.gov/biomass/pdfs/35523.pdf.

6. J.J. Bozell and G.R. Petersen, Green Chem., 12, 539 (2010); https://doi.org/10.1039/b922014c.

7. J.C. Serrano-Ruiz, J.M. Campelo, M. Francavilla, A.A. Romero, R. Luque, C. Menéndez-Vázquez, A.B. García and E.J. García-Suárez, Catal. Sci. Technol., 2, 1828 (2012); https://doi.org/10.1039/c2cy20217d. 
8. C.A. Roa Engel, A.J.J. Straathof, T.W. Zijlmans, W.M. van Gulik and L.A.M. van der Wielen, Appl. Microbiol. Biotechnol., 78, 379 (2008); https://doi.org/10.1007/s00253-007-1341-x.

9. H. Yi, L. Niu, S. Wang, T. Liu, A.K. Singh and A. Lei, Org. Lett., 19, 122 (2017);

https://doi.org/10.1021/acs.orglett.6b03403.

10. J. Zhang, S. Bao and J. Yang, Chin. Sci. Bull., 54, 3958 (2009); https://doi.org/10.1007/s11434-009-0437-3.

11. H. Aliyan, R. Fazaeli, A.R. Massah, A.R. Momeni, H.J. Naghash and B. Moeinifard, Asian J. Chem., 22, 873 (2010).

12. J.S. Yadav, B.V. Subba Reddy, R. Srinivas and T. Ramalingam, Synlett, 2000, 701 (2000); https://doi.org/10.1055/s-2000-6617.

13. Y. Lin., J. Shi, F. Zhang, Y. Zhong and W. Zhu, J. Mol. Catal. Chem., 383, 167 (2014); https://doi.org/10.1016/j.molcata.2013.12.005.

14. I.V. Kozhevnikov, Chem. Rev., 98, 171 (1998); https://doi.org/10.1021/cr960400y.
15. G.A. Tsigdinos, Top. Curr. Chem., 76, 1 (1978).

16. S.-S. Wang and G.-Y. Yang, Chem. Rev., 115, 4893 (2015); https://doi.org/10.1021/cr500390v.

17. L.C. Baker and D.C. Glick, Chem. Rev., 98, 3 (1998); https://doi.org/10.1021/cr9603921.

18. N. Mizuno and M. Misono, Chem. Rev., 98, 199 (1998); https://doi.org/10.1021/cr960401q.

19. D.E. Katsoulis, Chem. Rev., 98, 359 (1998); https://doi.org/10.1021/cr960398a.

20. C. Srilakshmi, N. Lingaiah, I. Suryanarayana, P.S.S. Prasad, K. Ramesh, B.G. Anderson and J.W. Niemantsverdriet, Appl. Catal. A Gen., 296, 54 (2005); https://doi.org/10.1016/j.apcata.2005.07.054.

21. M.N. Timofeeva, Appl. Catal. A., 256, 19 (2003); https://doi.org/10.1016/S0926-860X(03)00386-7. 